\title{
Urban wind energy conversion: the potential of ducted turbines
}

\author{
Andrew Grant, Cameron Johnstone and Nick Kelly \\ Energy Systems Research Unit, Department of Mechanical Engineering, \\ University of Strathclyde, 75 Montrose Street, Glasgow G1 1XJ, Scotland, UK
}

\begin{abstract}
The prospects for urban wind power are discussed. A roof-mounted ducted wind turbine, which uses pressure differentials created by wind flow around a building, is proposed as an alternative to more conventional approaches. Outcomes from tests at model and prototype scale are described, and a simple mathematical model is presented. Predictions from the latter suggest that a ducted turbine can produce very high specific power outputs, going some way to offsetting its directional sensitivity. Further predictions using climate files are made to assess annual energy output and seasonal variations, with a conventional small wind turbine and a photovoltaic panel as comparators. It is concluded that ducted turbines have significant potential for retro-fitting to existing buildings, and have clear advantages where visual impact and safety are matters of concern.
\end{abstract}

Keywords: urban wind; ducted turbine; buildings; pressure coefficients.

\section{Introduction}

Generating energy from the wind in an urban environment is an attractive idea. It places a source of supply at a site of strong energy demand, the essence of "embedded generation". However, there are major problems over its practical implementation at a significant scale. The EC-funded Project WEB [1] identified three possible strategies: -

- simply siting conventional free-standing wind turbines in an urban environment;

- retro-fitting wind turbines onto existing buildings;

- and integration of wind turbines into buildings which are specially designed for the purpose.

The first of these could perhaps be dismissed on semantic grounds, as the word "urban" by definition suggests large buildings in close proximity, with no space for free-standing wind turbines and certainly not for a reasonably clear fetch of wind to reach them.

Project WEB concentrated largely on the third strategy, producing designs and scale models of fully-integrated systems. From an aerodynamic point of view these seem to be quite effective. Public concerns over safety, and issues of noise and vibration might present barriers to progress. And of course implementation of this strategy requires new construction, so at best the growth of installed generating capacity would be very slow. 
Some progress has been made elsewhere with the second strategy. Urban wind characteristics are now being studied by the research community [2], and a number of manufacturers offer turbines for attachment to buildings. Again issues of noise, vibration and structural integrity arise, along with concerns over visual impact. Some commentators [3] remain sceptical of the ability of roof-mounted wind turbines to ever make a significant contribution to energy supply. Actual installations on buildings (admittedly at a fairly small scale) are appearing steadily [4], but the future remains uncertain: the potential consequences of a single well-publicised accident can easily be imagined.

Small wind turbines of any type inevitably have higher costs per unit of energy produced than wind-farm machines, and so are unable at present to compete with conventional sources of energy. But the same may be said of photovoltaic systems, and these are finding widespread application in urban environments throughout the world.

\section{The Ducted Wind Turbine}

The ducted wind turbine described here was envisaged from the outset as an alternative to conventional roof-mounted turbines, in the form of a building-integrated or retro-fitted module. The ducting protects the turbine from extremes of buildinggenerated turbulence, at the expense of directional sensitivity. The original concept (see Figure 1) came from a patent by Webster [5].

The curved duct and shaft drive of the original Webster patent makes sense for small turbines, where a hub-mounted generator would tend to block the air flow. Single units of this type have been built and tested over lengthy periods [6], and have proved effective and robust in operation. Figure 2 shows an early prototype under test in Glasgow city centre. Six machines were subsequently installed in the Lighthouse Building in Glasgow as part of an EC-funded demonstration project [7]; these had to be very small $(0.5 \mathrm{~m}$ rotor diameter $)$ for architectural reasons. The design adopted, seen in Figure 3, used an angled spoiler (fitted with a photovoltaic panel) to induce low pressures at the duct exit.

The underlying principle of operation of the device is the use of pressure differentials produced by the wind flow around and over a building to drive air through the ducted turbine. High pressures will be experienced on vertical walls facing the on-coming wind, and relatively low ones on the sides and rear. Locally, particularly around the roof, flow separation can induce extreme low pressures, widely recognised as potentially damaging due to their ability to lift tiles or other forms of cladding. These pressure differentials are a function of both wind speed and direction; the effect of speed may be compensated by referring to pressure coefficients of the form

$C_{P}=\frac{P}{\frac{1}{2} \rho V^{2}}$, where $P$ is the static pressure, $\rho$ is the air density and $V$ is conventionally the air speed in the atmospheric boundary layer at a level equal to the height of the building.

It might be possible to position a ducted turbine so that it experiences a large pressure differential for a wide range of incident wind directions.

Dannecker and Grant [8] have conducted wind tunnel tests on curved and straight ducts (without turbines) in a rectangular building model, measuring pressure coefficients and velocities within the duct. For certain configurations, the latter significantly exceeded the velocity of the approaching airstream. Importantly, these 
velocities were maintained over a wide range of incident angles, $\pm 60^{\circ}$ in the best cases. So the potential (at least in free ducts) has been demonstrated.

\section{Mathematical model}

For ducted wind turbines, there is a crucial inter-dependence between the turbine resistance, the mass flowrate through the duct and the pressure differential across its ends. In order to determine the requirements for optimum performance, and to predict power outputs for typical operating conditions, a mathematical model was developed.

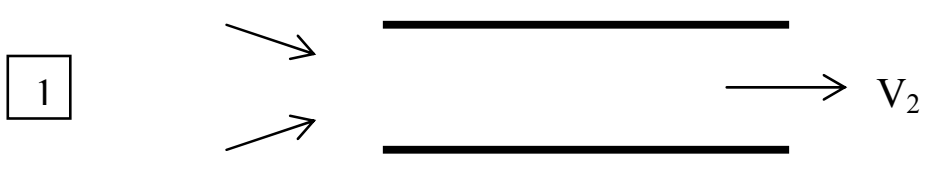

In a uniform unobstructed duct, the induced air velocity will be $V_{2}=C_{v} \sqrt{\frac{2\left(P_{01}-P_{2}\right)}{\rho}}$,

where $P_{01}$ is the stagnation pressure at duct inlet and $P_{2}$ is the static pressure at duct outlet. The air density is $\rho$ and $C_{v}$ is the velocity coefficient for the duct. If we define a differential pressure coefficient as $\quad \delta=\frac{P_{01}-P_{2}}{\frac{1}{2} \rho V_{\infty}^{2}}$, where $V_{\infty}$ is the approaching wind velocity, then $\quad V_{2}=C_{v} \sqrt{\delta} . V_{\infty}$

Values of the velocity ratio $V_{2} / V_{\infty}$ are plotted in Figure 4, for a range of values of $C_{v}$ and $\delta$. It will be argued later that $\delta$ values of 2 and more should be achievable in practice, in which case strong velocity amplification can take place even when there are significant losses in the duct.
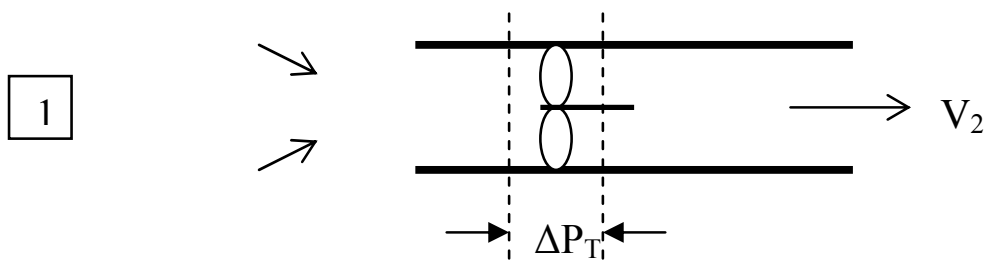

If a turbine is placed in the duct, causing a pressure drop $\Delta P_{T}$, the equation for the induced velocity becomes

$$
V_{2}=C_{v} \sqrt{\frac{2\left(P_{01}-P_{2}-\Delta P_{T}\right)}{\rho}}=C_{v} \sqrt{\delta V_{\infty}^{2}-\frac{2 \Delta P_{T}}{\rho}} .
$$

The power extracted by the turbine $=\frac{\Delta P_{T}}{\rho} \cdot \rho A V_{2}=\rho A V_{2}\left[\frac{\delta V_{\infty}^{2}}{2}-\frac{V_{2}^{2}}{2 C_{v}^{2}}\right]$, where

$A$ is the duct cross-sectional area. Differentiating with respect to $V_{2}$ gives a maximum 
power condition,

$\frac{\delta V_{\infty}^{2}}{2}-\frac{3 V_{2}^{2}}{2 C_{v}^{2}}=0, \quad$ or $\quad V_{2}=C_{v} \sqrt{\frac{\delta}{3}} \cdot V_{\infty}$

So when extracting power using a turbine, the optimum velocity ratio $V_{2} / V_{\infty}$ is reduced by a factor $\sqrt{3}$ from the value given in Equation (1) for an unobstructed duct. For maximum power, $\Delta P_{T}=\frac{1}{2} \rho\left[\delta V_{\infty}^{2}-\frac{\delta}{3} V_{\infty}^{2}\right]=\frac{1}{3} \rho \delta V_{\infty}^{2}$, and the power extracted from the airstream is $\frac{1}{3} \rho \delta V_{\infty}^{2} \cdot A C_{v} \sqrt{\frac{\delta}{3}} \cdot V_{\infty}=\frac{C_{v}}{3 \sqrt{3}} \rho A \delta^{3 / 2} V_{\infty}^{3}$.

The power coefficient $C_{P}=\frac{2}{3 \sqrt{3}} C_{v} \delta^{3 / 2}$

Figure 5 shows the relationship between $C_{P}, C_{v}$ and $\delta$. This suggests that in practical cases, $C_{P}$ values in excess of the Betz limit for free turbines might be expected. Values as high as 1 might be attained in some cases.

The $C_{P}$ values quoted here are of course gross ones (as in the Betz analysis for free wind turbines). The actual $C_{P}$ for any system must incorporate corrections for the rotor and generator efficiencies. In applying this theoretical model, it is necessary to make the assumption that values of the differential pressure coefficient $\delta$ are unaffected by the presence of the turbine duct: reasonably accurate for a single unit, more questionable for several grouped along the roof edge.

\section{Calibration of mathematical model}

Some aspects of the mathematical model may be checked against experimental measurements obtained by Dannecker [9]. He carried out a series of wind tunnel tests on a rectangular building model, fitted with ducts in various configurations. The case presented here had a circular duct angled at $30^{\circ}$ to the horizontal linking the front façade to the roof, and a detachable arched "spoiler" above the entrance (see Figure 6). Velocities were measured in the duct close to the exit, and compared with the reference wind speed: the ratio between the two is shown in Figure 7, for cases with and without spoiler. He also measured static pressures on the roof of the model, in the vicinity of the duct outlet. The duct was open, with no attempt to simulate a turbine by restricting the flow.

Looking first at the case where the spoiler was fitted, significant enhancement of velocity in the duct was observed: the velocity ratio $V_{2} / V_{\infty}$, averaged over the crosssectional area, was in the range 1.3 to 1.35 . The mean pressure coefficient at duct outlet was - 0.8 .

According to Equation (1), the velocity ratio should equal $C_{v} \sqrt{\delta}$ and if it is assumed that $C_{v}=1$, the $\delta$ value required to match the observed ratio lies in the range 1.69 to 1.82. A stagnation pressure coefficient at the duct inlet close to unity (which with a spoiler fitted is quite feasible) would give a $\delta$ value close to 1.8 and therefore within the required range. So the model appears to give an accurate representation in this case. It also indicates that the velocity coefficient $C_{v}$ for the duct must be high, certainly in excess of 0.9 , for the observed values of velocity ratio to be attained. 
In the case where the spoiler was removed, a reduced velocity ratio $V_{2} / V_{\infty}$ was observed (in the range 1.0 to 1.1 , averaged over the cross-sectional area). The mean pressure coefficient at the duct outlet was - 0.62. For $C_{v}=1$ in the duct, the $\delta$ value required to produce these velocity ratios lies in the range 1.0 to 1.21. So now the stagnation pressure coefficient at duct inlet is between 0.38 and 0.59 .

Certainly some reduction from the previous case would be expected: without the spoiler, the pressure coefficient on the front façade of a rectangular building will fall quite rapidly over its uppermost $20 \%$. It is also probable that the flow into the duct would be less well controlled, with stronger separation at the edges and hence greater dissipation of energy in the flow. So the most plausible explanation lies in some diminution of inlet pressure coefficient, and a reduced value of $C_{v}$. There are more uncertainties in this second case, but the mathematical model emerges unscathed.

\section{Pressure coefficients on buildings}

For best performance, the duct should link a high-pressure (stagnation) zone on the building with a region of very low pressure, caused perhaps by flow separation. Opportunities are likely at the sides of tall buildings, at the edges of flat roofs and near the ridge lines of pitched roofs.

Determination of the likely pressure coefficient differentials for these cases is not a straightforward matter. Building codes and guidelines are (quite understandably) primarily concerned with the structural integrity of roofing and cladding panels, and concentrate on peak $C_{P}$ values, both positive and negative. But for energy production from a ducted wind turbine, time-averaged values are more appropriate. Also it is becoming recognised that tests on models in wind tunnels do not give an accurate representation of pressure coefficients at full scale, particularly in regions of separated flow.

Hoxey et al. [10] investigated a building with a low-pitch roof at model and full scale, and concluded that patterns of flow separation on the roof and the position of the stagnation point on the front wall were both affected by scale. The widely held belief that flow around objects with sharp edges is immune from Reynolds number effects appears to be erroneous. Similar conclusions from modelling the decks of suspension bridges are reported by Larose and D'Auteuil [11].

Richards et al. [12] compared time-averaged $C_{P}$ measurements over the surfaces of a cube from a number of sources, with their own data for a $6 \mathrm{~m}$ cube as a "full-scale" reference. They concluded that $C_{P}$ values in separated regions are strongly influenced by scale: the larger the model, the lower the minimum pressure recorded on the roof. At full $(6 \mathrm{~m})$ scale, the minimum time-averaged value of $C_{P}$ was about -1.2 . For oblique flows where vortices were generated, scale effects appeared to be less significant.

The best opportunities for producing large pressure differentials seem to occur on flatroofed buildings, where the upwind façade might be linked to the separation bubble on the roof. Large pressure differentials may also be obtained on buildings with lowpitch roofs [13]. Steeper pitches, as investigated by Ginger and Holmes [14] at model scale, are best exploited near the ridge line. However, the fitting of ducted wind turbines onto pitched roofs is complicated by the fact that the ducts will significantly alter the appearance of the building, which may be unacceptable. Also, their attachment would involve the disturbance of cladding materials and might require the strengthening of roof timbers. 
For a flat-roofed building, it is clear from the literature that a high pressure differential can be maintained up to at least $45^{\circ}$ of misalignment with the approaching flow. The reduction in positive pressure on the façade of the building is more than compensated by the effect of edge vortices in reducing the static pressure on the roof. This is consistent with Dannecker's findings [9] on ducts in buildings at model scale. So the inherent directional sensitivity of a ducted turbine with fixed orientation is somewhat reduced.

\section{Ideas on exploitation}

The configurations investigated by Dannecker, while easy to reproduce in models, are only possible at full scale in a purpose-built structure. For widespread exploitation of the technology, designs to fit onto existing buildings are required.

Once more a promising application occurs around the edges of flat roofs. A straightduct module might be used, angled downward to intercept the air flow rising up the face of the building as shown in Figure 8. Here, the visual impact is similar to the adding of a parapet, and fixing should be less problematic. The ducts could be grouped in a row, or spaced at intervals within an otherwise solid wall.

Studies by Stathopoulos et al. [15] at model scale found that solid parapets had little effect on mean pressure coefficient values on a flat roof. This is in contrast to shortduration extreme values, which could be strongly affected. Interestingly, test by Kopp et al. [16] suggest that discontinuous parapets can affect vortex formation over flat roofs, altering the pressure distribution accordingly.

Porous parapets as investigated by Pindado and Meseguer [17], again at model scale, seem to reduce extreme negative pressures. The ducted turbine module in Figure 8 would behave like a porous parapet, so this finding is significant. There is clearly scope for more research, particularly at full scale.

The optimum size for a ducted turbine module will be a compromise between economies of scale (larger wind turbines are generally more cost-effective), ease of installation on existing buildings and visual impact (both of which would tend to limit size). Rotor diameters of $1 \mathrm{~m}$ or more should be practical: in this case, a streamlined duct and hub-mounted generator could be employed.

Ducted turbines at the edge of a flat roof should experience $\delta$ values of around 2 when the wind blows normal to the roof edge. With duct $C_{v}$ values close to 1 , aerodynamic power coefficients in excess of unity are possible (Figure 5). When losses in the generator and elsewhere are considered, overall power coefficients around 0.7 may be expected, about twice the figure for a conventional small wind turbine. A turbine module with a $1 \mathrm{~m}$ square duct and a somewhat smaller rotor diameter might be rated at around $250 \mathrm{~W}$ in a wind speed of $10 \mathrm{~m} / \mathrm{s}$. A roof-mounted array $20 \mathrm{~m}$ wide might therefore produce $5 \mathrm{~kW}$. But there is still some uncertainty about how the presence of a substantial ducted air flow might affect the pressure distribution around the building, and hence the effective value of $\delta$.

Vortex generation above the edges of a flat roof in oblique flows should ensure that turbine performance is maintained over at least $\pm 45^{\circ}$ variation in wind direction. But inevitably, there will be a wide range of angles over which a ducted turbine will produce zero output, so it suffers in comparison with a conventional roof-mounted wind turbine. But the latter must also experience directional effects to some extent: 
turbulence from adjacent buildings and local roof elements will vary in nature and severity with the wind direction, influencing the turbine's performance and perhaps also its longevity.

\section{Energy capture}

The relative performance of a number of building-integrated renewable energy converters has been investigated for climatic conditions in Glasgow, Scotland, UK. The devices considered were: a conventional small wind turbine mounted on the roof (WTG); two ducted turbines, facing South and West respectively; and a photovoltaic panel (PV), fixed at the optimum orientation for the latitude of Glasgow. Rotor diameter for all turbines was $1 \mathrm{~m}$, and the area of the photovoltaic panel was 'normalised' to equal the turbine rotor swept area. Hourly averaged data for wind speed and direction and solar radiation over a typical year were used to compute energy capture per month. The results are displayed in Figure 9.

There are a number of factors which might affect the accuracy of these predictions. Since power is proportional to the cube of wind velocity, the use of hourly averages is likely to be unkind to the wind turbines. No directional sensitivity has been attributed to the conventional turbine. Finally, assumptions have inevitably been made about turbine power coefficients and photovoltaic panel efficiency, which may or may not be accurate.

Figure 9 shows large differences in output for the two ducted turbine orientations, so determining the optimum alignment is clearly important. The expected complementary nature of wind and solar energy is clearly demonstrated. The annual totals for the 4 systems, in the order in which they appear in the Figure, are 156, 147, 219 and $85 \mathrm{kWh}$, corresponding to mean outputs (in W) of 17.8, 16.8, 25.0 and 9.7 respectively.

The West-facing ducted turbine produces roughly 50\% more energy over the year than its South-facing counterpart, and also out-performs the conventional wind turbine. However, the capacity factors for the ducted turbines will be comparatively low as a result of their higher rated power $(250 \mathrm{~W}$ as against $100 \mathrm{~W})$. The conventional turbine emerges with the highest capacity factor of 0.178 although as stated, no allowance was made for degradation of its performance in certain wind directions. This figure is still only about half the value routinely achieved in Scottish onshore wind farms, and highlights a key difficulty for urban wind exploitation: the quality of the wind regime makes cost-effective exploitation very difficult to accomplish.

\section{Conclusions}

It is claimed that ducted turbine modules can be a viable alternative to the practice of attaching small conventional machines to the roofs of existing buildings. Ducted wind turbines are protected from extremes of building-generated turbulence and have small visual impact. In the commercial and industrial sectors particularly, the potential scope is large.

A mathematical model has been developed to predict the performance of a buildingintegrated, ducted wind turbine. From the experimental evidence presently available, it seems to give an accurate representation. In the most promising applications, power 
coefficients well in excess of the conventional Betz limit should be attainable. However, the turbines are necessarily fairly small and are directionally sensitive.

At present, the combination of high cost per unit of rated power output and low capacity factor makes it difficult for urban wind energy to compete with other sources. But the same might be said about solar photovoltaics. In the longer term, energy cost convergence should bring about more widespread exploitation.

\section{References}

[1] Campbell $\mathrm{N}$ et al. Wind energy for the built environment (Project WEB). Proc. European Wind Energy Conference, Copenhagen, Denmark, July 2001.

[2] Mertens S. The energy yield of roof mounted wind turbines. Wind Engineering 2003; 27: 507-18.

[3] Gipe P (2003). Roof-top mounting. $\underline{\text { http://www.wind- }}$ works.org/articles/RoofTopMounting.html.

[4] Knight J. Urban wind power: breezing into town. Nature 2004; 430: 12-13.

[5] Webster GW, Glasgow, Scotland; Devices for Utilizing the Power of the Wind; USA Patent No. 4154556, 1979.

[6] Grant AD, Nasr el-Din SA, Kilpatrick J; Development of a Ducted Wind Energy Converter; Wind Engineering, Vol. 18, No. 6, 1994.

[7] RE-Start (Renewable Energy Strategies and Technologies for Regenerating Towns); Targeted project under the RUE (Rational Use of Energy) in the building sector; THERMIE programme, $4^{\text {th }}$ framework 1996; Commission of the European Communities, DG XVII, Directorate-General for Energy and Transport.

[8] Dannecker RKW, Grant AD. Investigations of a building-integrated ducted wind turbine module. Wind Energy 2002; 5: 53-71.

[9] Dannecker RKW. Wind energy in the built environment: an experimental and numerical investigation of a building-integrated ducted wind turbine module. $\mathrm{PhD}$ thesis, University of Strathclyde, Glasgow, UK, 2001.

[10] Hoxey RP, Robertson AP, Richardson GM, Short JL. Correction of wind tunnel pressure coefficients for Reynolds number effect. J. Wind Engineering \& Industrial Aerodynamics 1997; 69-71: 547-55.

[11] Larose GL, D'Auteuil A. On the Reynolds number sensitivity of the aerodynamics of bluff bodies with sharp edges. J. Wind Engineering \& Industrial Aerodynamics 2006; 94: 365-376.

[12] Richards PJ, Hoxey RP, Short JL. Wind pressures on a $6 \mathrm{~m}$ cube. J. Wind Engineering \& Industrial Aerodynamics 2001; 89: 1553-64.

[13] Kumar KS, Stathopoulos T. Wind loads on low building roofs: a stochastic perspective. J. Structural Engineering 2000; 126: 944-56.

[14] Ginger JD, Holmes JD. Effect of building length on wind loads on low-rise buildings with a steep roof pitch. J. Wind Engineering \& Industrial Aerodynamics 2003; 91: 1377-1400.

[15] Stathopoulos T, Saathoff P, Du X. Wind loads on parapets. J. Wind Engineering \& Industrial Aerodynamics 2002; 90: 503-14.

[16] Kopp GA, Surry D, Mans C. Wind effects of parapets on low buildings: Part 1. Basic aerodynamics and local loads. J. Wind Engineering \& Industrial Aerodynamics 2005; 93: 817-841. 
[17] Pindado S, Meseguer J. Wind tunnel study on the influence of different parapets on the roof pressure distribution of low-rise buildings. J. Wind Engineering \& Industrial Aerodynamics 2003, 91: 1133-39.

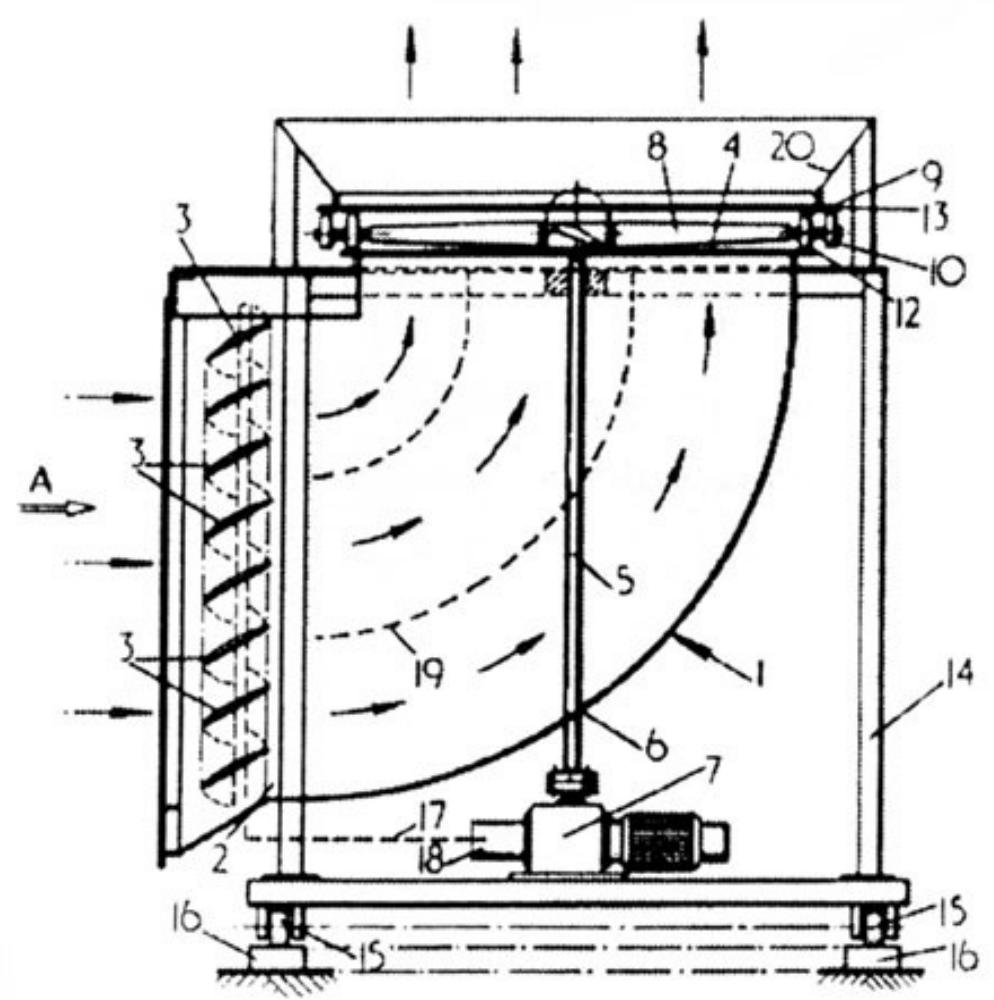

Figure 1: Original ducted wind turbine from patent by Webster [5] 


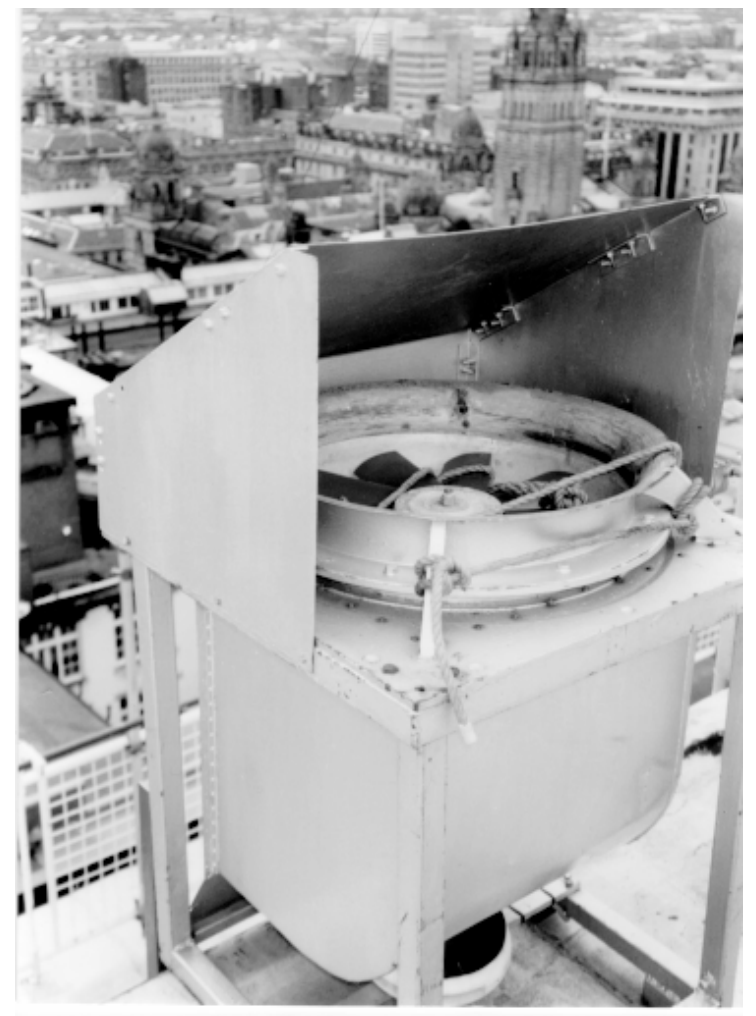

Figure 2: Early ducted turbine prototype under test at University of Strathclyde, Glasgow

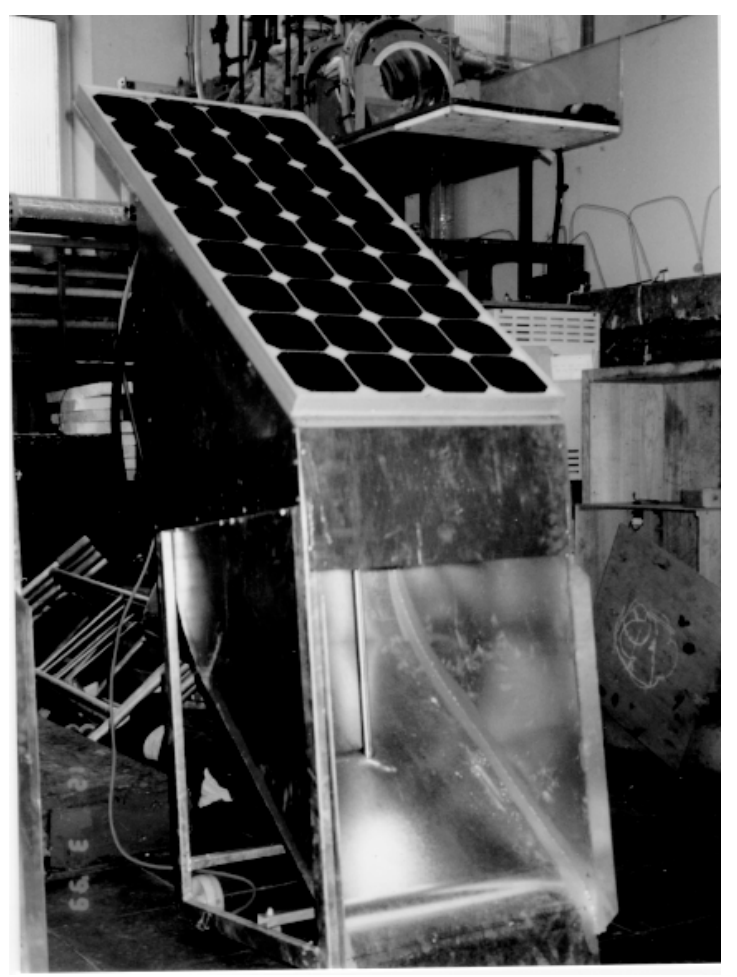

Figure 3: Ducted wind turbine module as installed on the Lighthouse building, Glasgow 


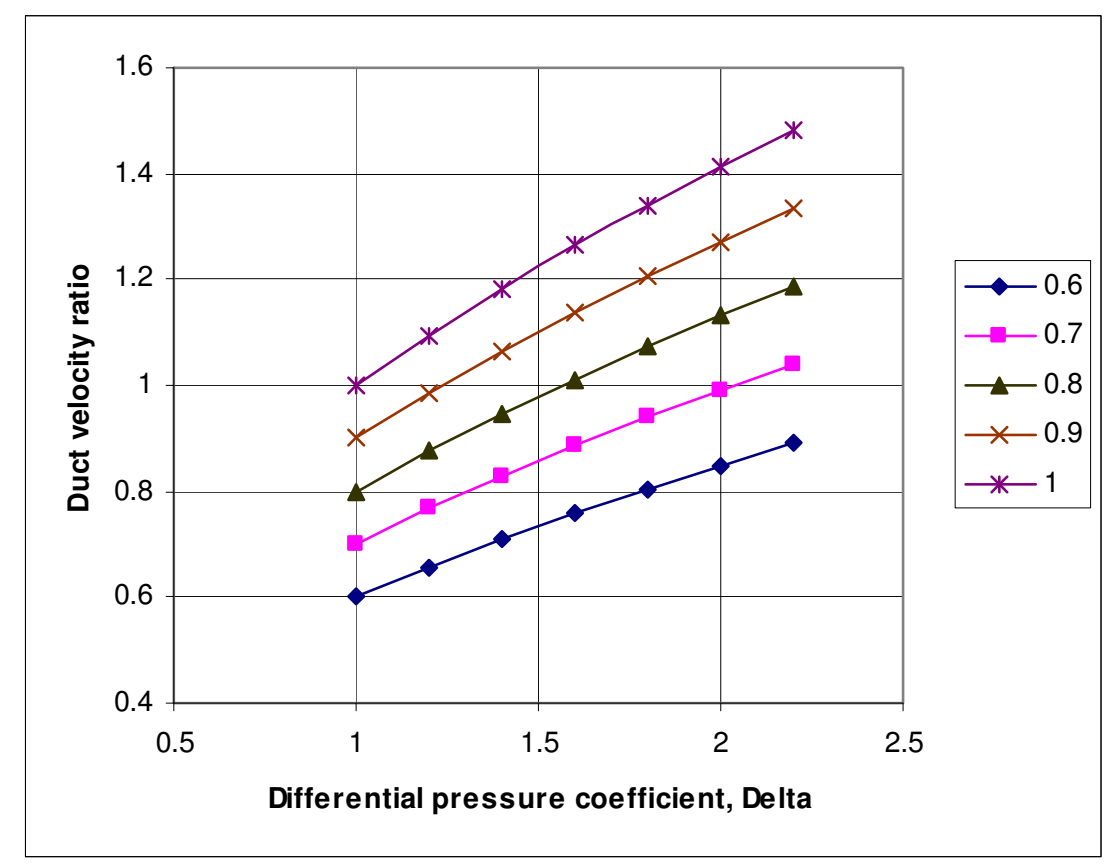

Figure 4: Velocity augmentation in a free duct, for a range of pressure differentials. A number of duct $C_{v}$ values are considered (see legend)

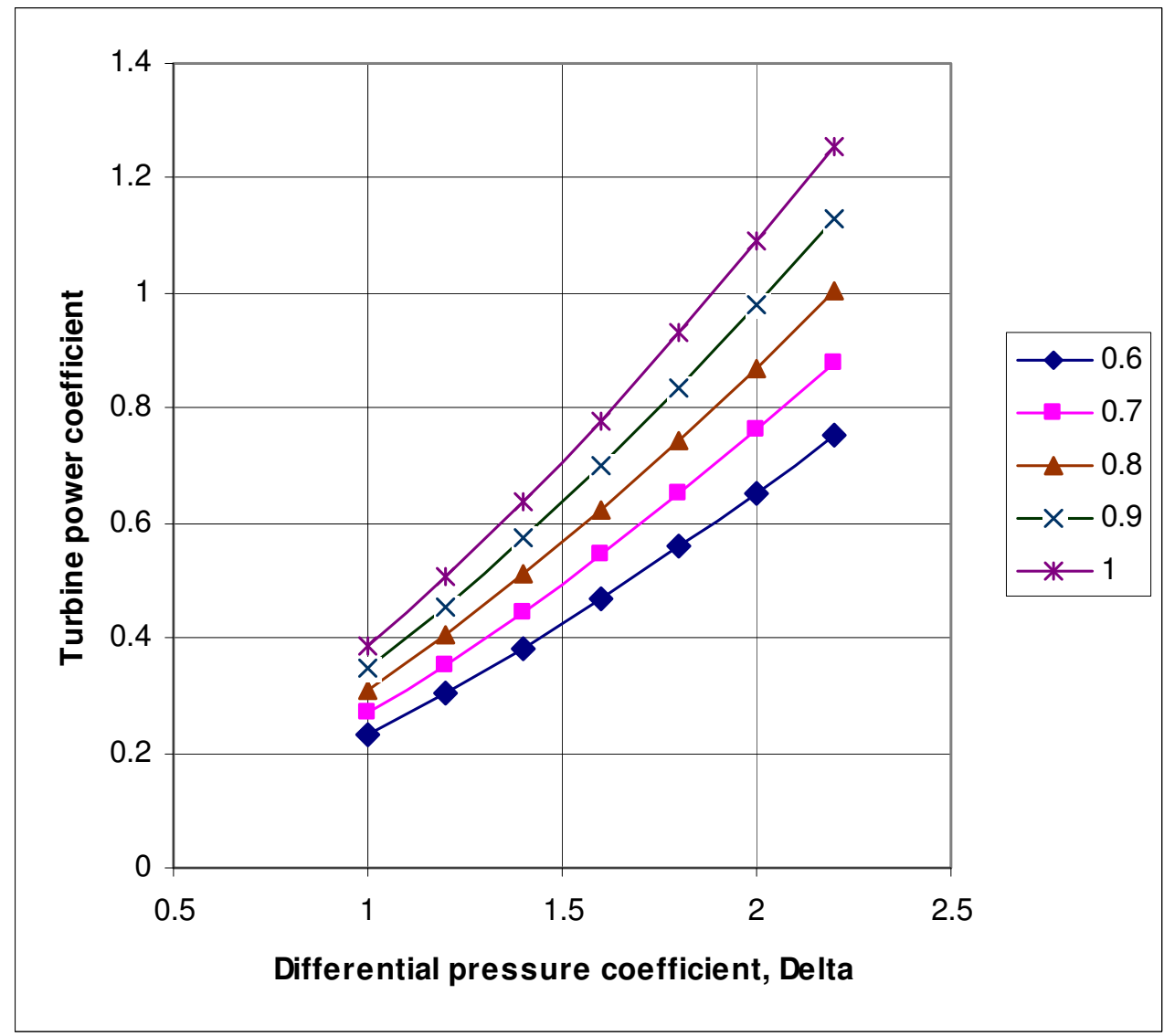

Figure 5: Predicted turbine power coefficients, for a range of pressure differentials. A number of duct $C_{v}$ values are considered (see legend) 


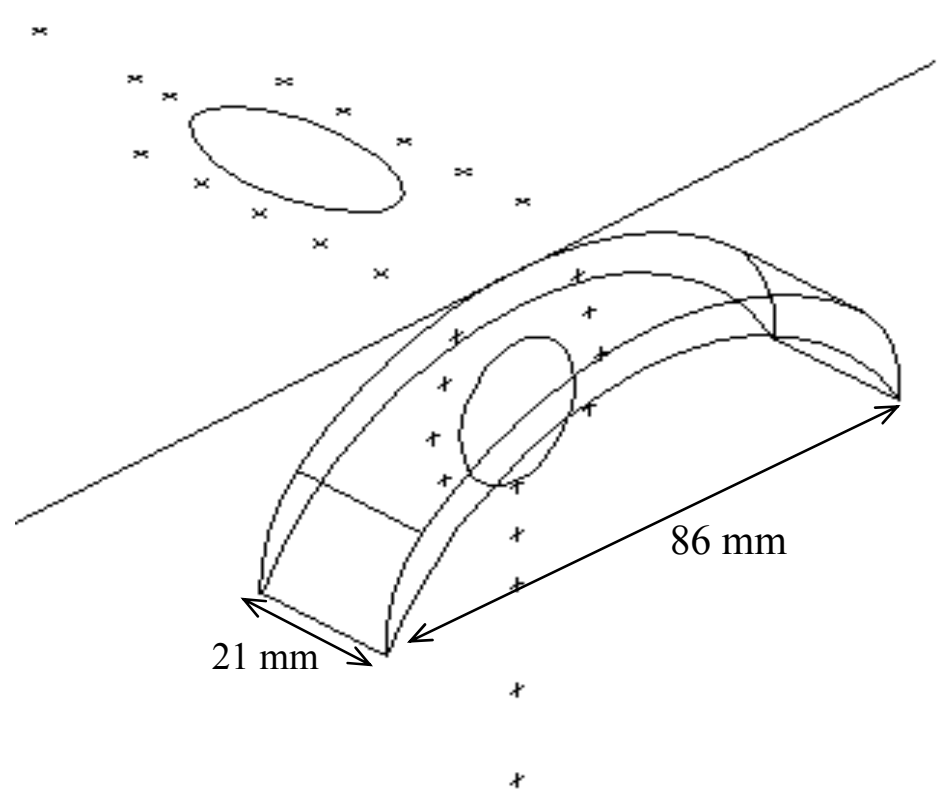

Figure 6: Three dimensional view of $30^{\circ}$ straight duct with wide spoiler at the inlet

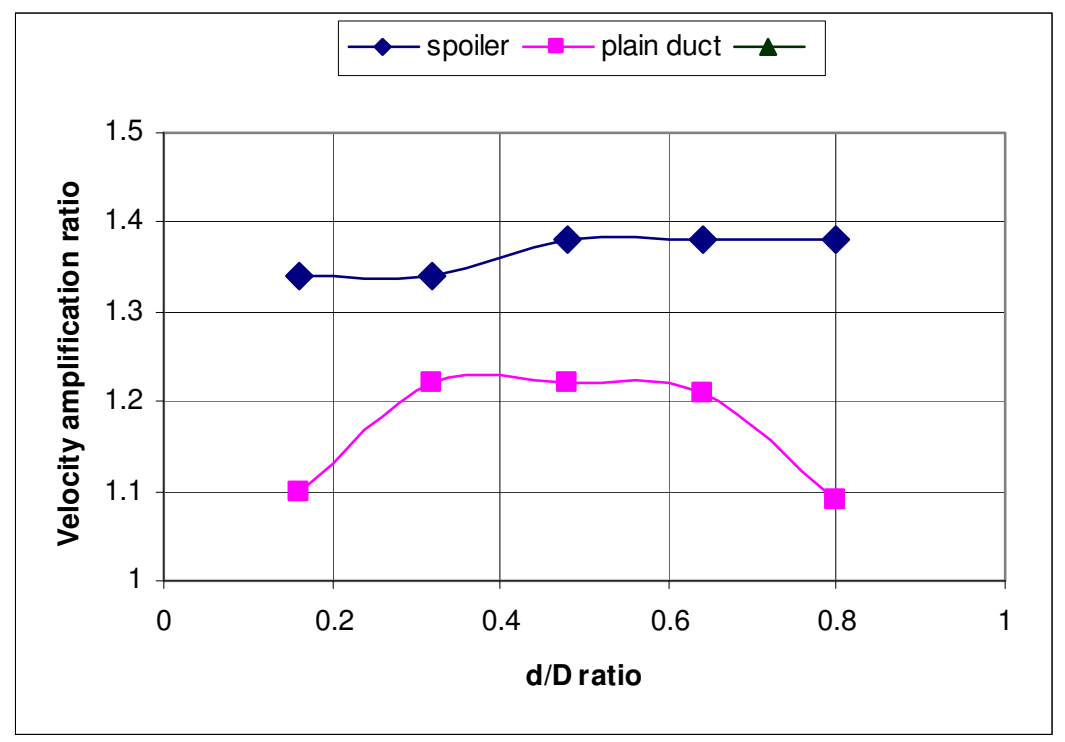

Figure 7: Measured velocity distributions for the duct shown in Figure 5 


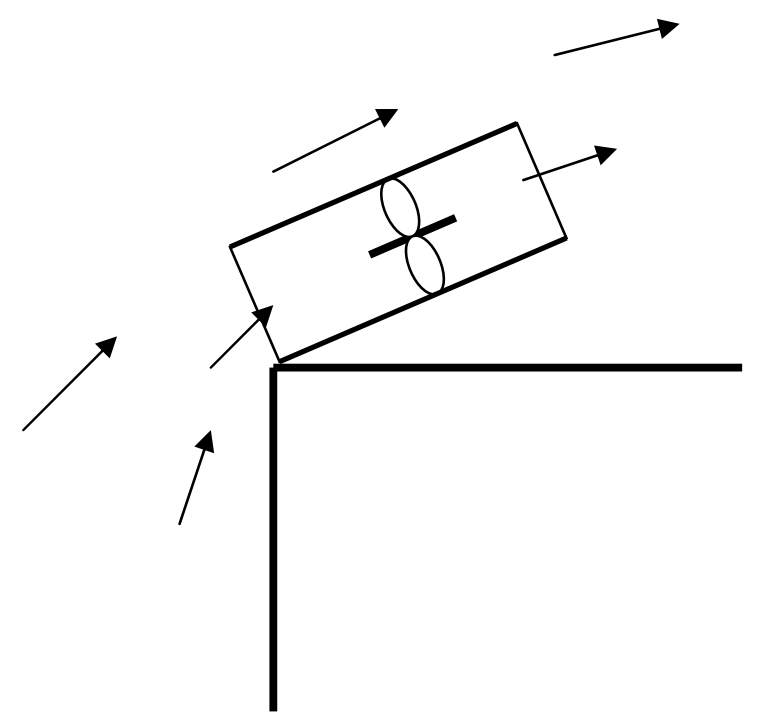

Figure 8: Angled straight duct to intercept air flow at the edge of a flat roof

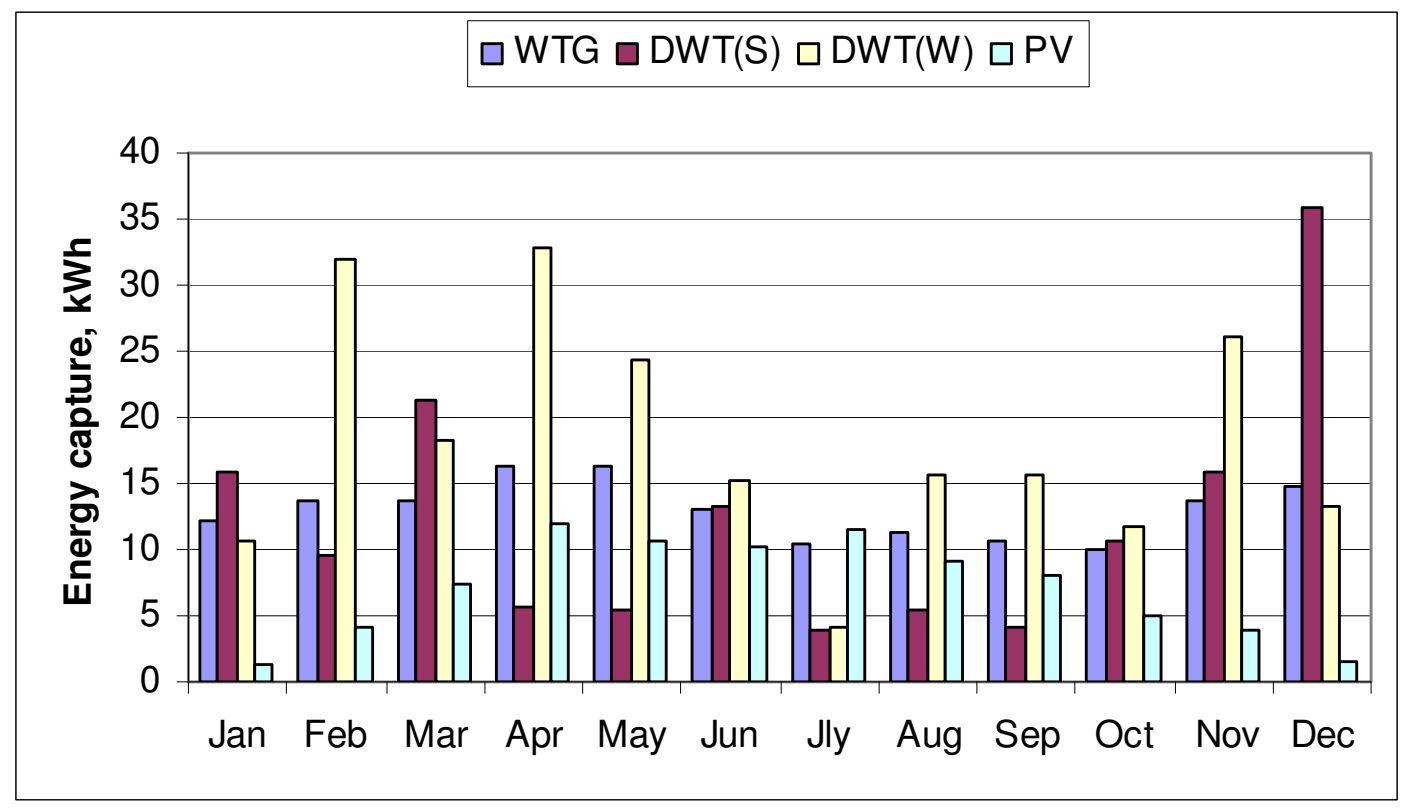

Figure 9: Energy capture predictions for ducted wind turbines in 2 orientations, compared with a conventional turbine and a photovoltaic panel (Glasgow climatic data) 